\title{
FRONTEIRAS ${ }^{1}$
}

THOMAS KING ${ }^{2}$

Quando eu tinha doze ou talvez treze anos, minha mãe anunciou que iríamos a Salt Lake City visitar minha irmã, que tinha deixado a reserva, cruzado a fronteira e arranjado um trabalho. Laetitia não saiu de casa com a benção de minha mãe, mas com o tempo minha mãe acabou se orgulhando do fato de Laetitia ter feito tudo isso sozinha.

"Ela se saiu muito bem", minha mãe dizia.

E então, havia os detalhes da ida de Laetitia. Ela não tinha ido como minha mãe gostava de dizer a senhora Manyfingers - atrás de um homem, como um balão preso a uma corda. Também não tinha fugido de casa e ido para Vancouver ou Edmonton ou Toronto procurando a recompensa no final do arco-íris. E não tinha ficado grávida. "Ela se saiu muito bem".

\footnotetext{
${ }^{1}$ Traduzido por Renata Bertini.

${ }^{2}$ Nascido nos Estados Unidos (Sacramento, Califórnia), de ascendência cherokee, grega e alemã, mas morando atualmente no Canadá, onde leciona na Universidade de Guelph (Guelph, Ontário), Thomas King, tal como os Blackfoot, com quem conviveu, pertence, por assim dizer, a ambos os lados da fronteira. Não por acaso, seu romance Truth and Bright Water [referindo-se ao nome de duas cidades fictícias situadas em lados opostos da fronteira entre os Estados Unidos e Canadá, 1999] explora essa complexa relação de quem circula em um território que é, na verdade, único. Assim Thomas King dirige seu olhar para as relações pan-indígenas e as complexidades dessa realidade na contemporaneidade, em que leis de exclusão, preconceitos e o pesado legado histórico ainda fazem parte do cotidiano indígena, seja para os nativos americanos, seja para as nações primeiras do Canadá. Repleto de humor, suas obras nada possuem do índio reificado pelas imagens cinematográficas, porém brincam com as mesmas, produzindo situações próprias de um trickster disposto a denunciar injustiças e se reiventar em pleno poder de suas histórias. O presente conto, parte integrante de sua coletânia One Good Story, That One [Boa História, Essa aí, 1993], é uma introdução breve mas exemplar a este narrador de histórias, que nos faz ouvir uma série de níveis, dos mais leves e cotidianos aos mais sérios, entre uma risada e outra. Além de contos, romances, histórias infantis e roteiros, King criou um show radiofônico, o The Dead Dog Cafe Comedy Hour [A Hora da Comédia na Cafeteria do Cachorro Morto], que foi ao ar de 1997 a 2000, na CBC, com duas sequências, uma em 2002 e outra em 2006. Em 2003, foi selecionado para as Palestras Massey da CBC (Canadian Broadcasting Corporation), mais tarde publicada sob o título The Truth About Stories: A Native Narrative [A Verdade sobre as Histórias: Uma Narrativa Nativa, 2005] (uma delas a ser publicada oportunamente na Revista Espaço Ameríndio).
}

Espaço Ameríndio, Porto Alegre, v. 7, n. 2, p. 240-252, jul./dez. 2013. 
Eu tinha sete ou oito anos quando Laetitia saiu de casa. Ela, dezessete. Nosso pai era de Rocky Boy, do lado americano.

"Papai é americano", Laetitia disse a minha mãe, "então, eu posso ir e vir quando quiser".

"Nos mande um cartão postal".

Laetitia arrumou suas coisas, e fomos para a fronteira. Logo depois que passsamos o rio Milk, Laetitia nos disse para prestar atenção à torre de água.

"Depois da próxima subida. É a primeira coisa que vocês vão ver".

"Nós temos uma torre de água na reserva também", minha mãe disse. "Também tem uma grande em Lethbridge".

"Vocês também vão ver o topo dos mastros das bandeiras. É lá que está a fronteira".

Quando chegamos a Coutts, minha mãe parou na loja de conveniências e trouxe café para ela e para Laetitia. Para mim, trouxe um refrigerante de laranja.

"Esse café é péssimo".

"Você está irritada porque eu quero ver o mundo".

"É a água. Daqui pra baixo, a água deles é péssima".

"Posso pegar um ônibus em Sweetgrass. Você não precisa mover um dedo".

"Você terá que comprar água em garrafa se quiser um bom café".

Havia uma casa antiga de madeira a cerca de uma quadra de distância, com uma placa alta no jardim que dizia "Museu". A maior parte do telhado tinha sido levada pelo vento. Minha mãe me disse para ir ver o horário que ele abria. Havia tábuas nas janelas e nas portas. Dava para ver que o lugar estava fechado, e eu disse isso para minha mãe, mas ela disse para eu verificar mesmo assim. Minha mãe e Laetitia ficaram no carro. Nenhuma delas se moveu. Sentei nos degraus do museu e fiquei observando elas, e não sei se, em algum momento, elas disseram alguma coisa uma para a outra. Finalmente, Laetitia tirou sua sacola do porta-malas e deu um abraço na mãe.

Voltei devagar para o carro. Começou a ventar, e o vento aumentou de intensidade e soprou os cabelos de Laetitia sobre seu rosto. Minha mãe se aproximou e tirou os fios dos olhos dela, e Laetitia deixou.

Espaço Ameríndio, Porto Alegre, v. 7, n. 2, p. 240-252, jul./dez. 2013. 
"Você ainda pode ver a montanha daqui", minha mãe disse à Laetitia em blackfoot.

"Há muitas montanhas em Salt Lake", disse Laetitia em inglês.

"O lugar está fechado", eu disse. "Como eu tinha dito".

Laetitia enfiou os cabelos dentro do casaco e arrastou sua sacola pela estrada em direção ao prédio de tijolos com a bandeira norteamericana ondulando no mastro. Quando ela chegou onde os guardas estavam esperando, ela se virou, largou sua sacola e abanou para nós. Nós abanamos de volta. Depois minha mãe manobrou o carro e voltamos para casa.

Nós recebíamos cartões postais da Laetitia regularmente e, se não estava dourando a pílula, ela estava feliz. Tinha conseguido um bom emprego e alugou um apartamento com piscina.

"E ela nem sabe nadar", disse minha mãe à senhora Manyfingers.

A maioria dos cartões dizia que devíamos ir ver a cidade, mas, sempre que eu falava sobre isso, minha mãe enrijecia.

Por isso, fiquei surpreso quando ela comprou dois pneus novos para o carro e colocou seu vestido azul com flores verdes e amarelas. Tive que me arrumar também, pois minha mãe não queria que nós cruzássemos a fronteira parecendo americanos. Fizemos sanduíches e os colocamos numa caixa grande com refrigerante e batatinhas, algumas maçãs e bananas e uma grande garrafa de água.

"Mas nós podemos parar num daqueles restaurantes também, não é?"

"Talvez nós devêssemos pegar um cobertor, caso você fique com sono".

"Mas nós podemos parar num daqueles restaurantes também, não é?"

A fronteira era, na verdade, duas cidades, embora nenhuma delas fosse grande o suficiente para ser alguma coisa. Coutts ficava no lado canadense e era formada pela loja de conveniências, pelo posto de gasolina, pelo museu, que estava fechado e cheio de tábuas, e pelo motel. Sweetgrass ficava no lado americano, mas tudo que se podia enxergar era uma elevada se arqueando sobre a estrada e desaparecendo nas pradarias. Ao ouvir os nomes dessas cidades, era de se esperar que Sweetgrass, que é um nome agradável e que parece estar 
relacionado a outros lugares como Medicine Hat e Moose Jaw e Kicking Horse Pass, seria do lado canadense, e que Coutts, que soa áspero e rude, seria do lado americano. Mas não era esse o caso.

Entre as duas cidades havia um free shop onde se podia comprar cigarros, bebidas e bandeiras. Essas coisas.

Saímos da reserva de manhã e fomos até Coutts.

"Na última vez que paramos aqui", disse minha mãe, "você tomou um refrigerante de laranja. Você lembra disso?"

"Claro", eu disse. "Isso foi quando a Laetitia foi embora".

"Você quer outro refrigerante de laranja?"

"Isso significa que nós não vamos parar num restaurante, não é?"

Minha mãe pegou um café na loja de conveniências e ficamos ali, observando as pradarias se mexendo sob a luz do sol. Depois, voltamos para o carro. Minha mãe ajeitou o vestido sobre suas coxas, se inclinou sobre o volante e dirigiu até a fronteira na primeira marcha, devagar, como se tentasse enxergar em meio a uma tempestade ou dirigindo sobre o gelo escuro.

O guarda da fronteira era um velho. À medida que andava em direção ao carro, oscilava de um lado para o outro com os pés bem distantes um do outro e o coldre em sua cintura balançando para cima e para baixo. Ele se inclinou na janela, olhou para o banco de trás e depois para minha mãe e para mim.

"Bom dia, senhora".

"Bom dia".

"Vocês estão indo para onde?"

"Salt Lake City".

"Motivo da visita?"

"Visitar minha filha".

"Nacionalidade?"

"Blackfoot", minha mãe disse a ele.

"Como?"

"Blackfoot", ela repetiu.

"Canadense?"

"Blackfoot".

Teria sido mais fácil se minha mãe tivesse simplesmente dito "canadense" e terminado logo com aquilo, mas eu percebi que ela não ia 
fazer isso. O guarda não ficou irritado ou coisa parecida. Ele sorriu e olhou em direção ao prédio. Depois, olhou de volta e acenou com a cabeça.

"Boa dia, senhora".

"Bom dia".

"Alguma arma de fogo ou tabaco?"

"Não".

"Nacionalidade?"

"Blackfoot".

Ele nos disse para aguardar no carro, e ficamos esperando. Uns cinco minutos depois, outro guarda saiu do prédio junto com o primeiro. Enquanto vinham, eles conversavam, ambos oscilando de um lado para o outro, como cowboys se dirigindo a um bar ou duelo.

"Bom dia, senhora".

"Bom dia".

"Cecil me disse que você e o garoto são blackfoot".

"Isso mesmo".

"Sei que temos blackfoot no lado americano e os canadenses têm blackfoot no lado deles. Só para manter o registro, de que lado você vem?"

Eu sabia exatamente o que minha mãe ia dizer e podia ter dito a eles se tivessem me perguntado.

"Lado canadense ou lado americano?", perguntou o guarda.

"Lado blackfoot".

Não demorou muito para eles perderem o senso de humor. 0 guarda parou de sorrir, e pediu que estacionássemos o carro ao lado do prédio e entrássemos.

Sentamos num banco de madeira por mais ou menos uma hora até alguém vir falar conosco. Dessa vez era uma mulher. Ela também tinha uma arma.

"Oi", ela disse. "Sou a agente Pratt. Fui informada de que há um pequeno mal-entendido".

"Vou visitar minha filha em Salt Lake City", disse minha mãe. "Nós não temos armas nem cerveja".

"É apenas uma questão técnica legal".

"Minha filha também é blackfoot". 
A mulher abriu uma pasta, pegou alguns formulários e começou a escrever num deles. "Todos que cruzam nossas fronteiras devem declarar sua nacionalidade. Até mesmo americanos. Isso nos ajuda a manter o registro dos visitantes que recebemos de diversos países".

Ela continuou com aquilo por uns quinze minutos, e muitas das coisas que ela nos contou eram interessantes.

"Entendo como você se sente tendo que nos informar sua nacionalidade, por isso vou fazer o seguinte: você me diz, e eu não vou colocar no formulário. Ninguém vai saber, só eu e você".

A arma dela era prateada. Havia várias marcas na coronha de madeira e o nome "Stella" estava rabiscado na parte de metal.

Ficamos no escritório da fronteira por umas quatro horas e falamos com quase todos lá dentro. Um dos homens me comprou uma coca-cola. Minha mãe trouxe dois sanduíches do carro. Ofereci um pedaço do meu à Stella, mas ela disse que não estava com fome.

Eu disse à Stella que nós éramos blackfoot e canadenses, mas ela disse que isso não contava porque eu era menor. No fim, ela disse que, se minha mãe não declarasse sua nacionalidade, teríamos que voltar para o lugar de onde viemos. Minha mãe levantou e agradeceu Stella por seu tempo. Então, voltamos para o carro e fomos para a fronteira canadense, que ficava a cerca de apenas noventa metros dali.

Eu estava decepcionado. Não via Laetitia há muito tempo e nunca tinha ido a Salt Lake City. Quando ainda estava em casa, Laetitia falava o tempo inteiro de Salt Lake City. Ela nunca tinha estado lá, mas o namorado dela, Lester Tallbull, tinha passado um ano na escola técnica de Salt Lake City.

"É um lugar ótimo", dizia Lester. "Nada a não ser loiras em todo o estado".

Toda vez que ele dizia isso, Laetitia batia no ombro dele com força o suficiente para fazê-lo se curvar. Ele tinha alguns panfletos sobre Salt Lake City e alguns mapas, e, de vez em quando, eles os espalhavam em cima da mesa.

"Este é o templo. É bem no centro. Você precisa de um passe para entrar".

"Charlotte disse que qualquer um pode entrar e dar uma olhada". 
"Quando Charlotte foi a Salt Lake City? Me diz, quando é que ela esteve em Salt Lake City?"

"Ano passado".

"Este é o Liberty Park. Tem um zoológico e dá pra esquiar legal nas montanhas".

"Aqui podemos esquiar à vontade", dizia minha mãe. "As pessoas vêm de todos os lugares do mundo para esquiar em Banff. Há um templo em Cardston, se você gosta dessas coisas".

"Ah, mas esse é um parque muito grande", Lester dizia. "Eles tem guardas armados e tudo mais".

"Não foi o que Charlotte disse".

Lester e Laetitia terminaram. Mas acho que a ideia de Salt Lake City ficou na cabeça dela.

O guarda da fronteira canadense era uma mulher jovem e parecia feliz em nos ver. "Oi", ela disse. "Vocês escolheram um lindo dia para viajar. De onde vocês estão vindo?"

"Standoff".

"Isso fica em Montana?"

"E para onde vocês estão indo?"

"Standoff".

O nome dela era Carol, e acho que ela não era mais velha que Laetitia. "Nossa, vocês são canadenses?"

"Blackfoot".

"Mesmo? Tenho um amigo que ia para a escola comigo que é blackfoot. Vocês conhecem Mike Harley?"

"Não".

"Ele ia à escola em Lethbridge, mas, na verdade, era de Browning".

Foi uma conversa legal e não havia ninguém atrás de nós; por isso, não havia pressa.

"Vocês não estão trazendo álcool aí atrás, não é?"

"Não".

"Cigarros, plantas ou algo assim?"

"Não".

"Nacionalidade?"

"Blackfoot". 
"Eu sei", disse a mulher, "e eu ficaria orgulhosa de ser blackfoot se eu fosse blackfoot. Mas vocês têm que ser canadenses ou americanos".

Quando Laetitia e Lester terminaram, Lester levou seus panfletos e seus mapas com ele, então Laetitia escreveu para alguém em Salt Lake City e, cerca de um mês depois, ela recebeu um envelope cheio de coisas. Sentamos à mesa e abrimos todos os panfletos, e Laetitia leu cada um deles em voz alta.

"Salt Lake City é a porta de entrada para um dos lugares mais magníficos do mundo para esquiar".

"Salt Lake City é o berço de uma das mais novas franquias do basquete profissional, o Utah Jazz".

"O Grande Lago Salgado é uma das maravilhas naturais do mundo".

Era emocionante ver todos aqueles panfletos coloridos na mesa e ouvir Laetitia ler sobre como Salt Lake City era um dos melhores lugares do mundo.

"Essa tal de Salt Lake City parece bom demais pra ser verdade", minha mãe disse.

"Tem tudo lá".

"Nós temos tudo bem aqui".

"É chato aqui".

"As pessoas em Salt Lake City provavelmente estão, agora mesmo, mandando cartas pedindo panfletos sobre Calgary, Letherbridge e Pincher Creek".

No final, minha mãe dizia que talvez Laetitia devesse ir para Salt Lake City, e Laetitia dizia que talvez ela fosse mesmo.

Estacionamos o carro ao lado do prédio, e Carol nos levou para uma sala pequena no segundo andar. Encontrei um lugar confortável no sofá e folheei algumas edições antigas de Saturday Night e Alberta Report.

Quando acordei, minha mãe estava saindo de outra sala. Ela não me disse uma palavra. Eu a segui pelas escadas até o carro. Achei que nós estávamos indo para casa, mas ela manobrou o carro e voltou para a fronteira americana, o que me fez pensar que nós íamos, afinal, visitar Laetitia em Salt Lake City. Ao invés disso, entrou com o carro no estacionamento do free shop e parou. 
"Nós vamos visitar a Laetitia?"

"Não".

"Estamos indo para casa?"

É bom ter orgulho, sabe. Laetitia sentia muito orgulho e minha mãe também. Eu imaginava que, algum dia, também teria.

"Então pra onde estamos indo?"

Durante grande parte do dia, ficamos andando pelo free shop, que não era muito grande. O gerente tinha uma plaquinha com uma bandeira canadense de um lado e uma norte-americana do outro. $\mathrm{O}$ nome dele era Mel. Quando chegou a noite, ele começou a sugerir que nós devíamos ir. Eu disse a ele que não tínhamos para onde ir, que nem os americanos ou os canadenses nos deixavam entrar. Ele riu disso e disse que nós devíamos comprar alguma coisa ou ir embora.

Não estava muito confortável no carro, mas tínhamos toda aquela comida e era abril, por isso, mesmo que nevasse - como, às vezes, neva nas pradarias - nós não congelaríamos. Na manhã seguinte, minha mãe dirigiu até a fronteira americana.

Era um guarda diferente dessa vez, mas as perguntas eram as mesmas. Não ficamos no escritório o mesmo tempo que ficamos no dia anterior. Perto do meio-dia, estávamos de volta à fronteira canadense. Pelas duas da tarde, estávamos de novo no estacionamento do free shop.

A segunda noite no carro não foi tão divertida quanto a primeira, mas minha mãe parecia estar de bom humor, e, no final das contas, aquilo era tanto uma aventura quanto era desagradável. Não sobrava muita comida e isso era um problema, mas nós tínhamos muita água, pois havia uma torneira ao lado do free shop.

Num domingo, Laetitia e eu estávamos assistindo televisão. Minha mãe estava na senhora Manyfingers. No meio do programa, Laetitia desligou a TV e disse que ia para Salt Lake City, que a vida ali era muito entediante. Eu queria assistir o resto do programa e realmente não me importava se Laetitia ia para Salt Lake City ou não. Quando minha mãe chegou em casa, eu disse a ela o que Laetitia havia dito.

O que me surpreendeu foi o quão irritada Laetitia ficou quando descobriu que eu havia contado para minha mãe.

"Você é um boca grande". 
"Foi o que você disse".

"O que eu disse não é da sua conta".

"Eu não falei nada".

"Bom, agora eu vou mesmo".

Naquele final de semana, Laetitia arrumou suas malas, e nós a levamos até a fronteira.

Mel se revelou um cara legal. Quando ele fechou a loja à noite e nos encontrou ainda parados no estacionamento, veio até nós e perguntou se o carro tinha estragado ou algo assim. Minha mãe agradeceu pela preocupação dele e disse que estávamos bem, que tudo se ajeitaria pela manhã.

"É brincadeira", disse Mel. "A gente pensa que eles conseguem lidar com coisas simples".

"Nós temos maçãs e bananas", eu disse, "mas estamos sem sanduíches de presunto".

"Sabe, você lê sobre essas coisas, mas não acredita. Simplesmente não acredita".

"Seria ainda melhor se tivéssemos hambúrgueres, porque eles têm mais coisas para dar energia".

Minha mãe dormiu no banco de trás. Eu dormi na frente porque eu era menor e conseguia deitar embaixo do volante. Tarde da noite, ouvi minha mãe abrir a porta do carro. Vi ela sentada em seu cobertor, encostada no para-choque do carro.

"Está vendo todas essas estrelas?", disse ela. "Quando eu era pequena, minha avó levava eu e minhas irmãs para as pradarias e nos contava histórias sobre as estrelas".

"Você acha que Mel vai nos trazer hambúrgueres?"

"Cada uma dessas estrelas tem uma história. Está vendo aquele monte de estrelas ali que parecem um peixe?"

"Ele não disse que não".

"Um dia, o coiote foi pescar. Foi assim que tudo começou". Ficamos sentados sob a luz das estrelas aquela noite, e minha mãe me contou todo o tipo de histórias. Ela levava aquilo a sério. Ela as contava devagar, repetindo algumas partes enquanto continuava, como se esperasse que eu me lembrasse de cada uma delas. 
Na manhã seguinte bem cedo, as vans da televisão começaram a chegar, e homens de terno e mulheres de vestido, dispararam em nossa direção, carregando microfones, câmeras e luzes com eles. Uma das vans tinha uma mesa posta, com suco de laranja, sanduíches e frutas. Era para a equipe, mas, quando eu disse a eles que não comia há algum tempo, uma mulher loira e realmente magra nos disse que podíamos comer o quanto quiséssemos.

Falaram mais com minha mãe. De vez em quando, um dos repórteres se aproximava e me perguntava como era ser um índio sem país. Eu disse a eles que nós tínhamos uma bela casa na reserva e que meus primos tinham alguns cavalos, que nós montávamos quando íamos pescar. Algumas das pessoas da televisão foram até a fronteira americana e depois foram até a fronteira canadense.

Por volta do meio-dia, um homem bonito num terno azulmarinho e uma gravata laranja com patinhos chegou num carro chique. Conversou com minha mãe por um tempo e, depois que eles terminaram de conversar, minha mãe me chamou e entramos no carro. Assim que minha mãe girou a ignição, Mel veio e nos deu um saco de pé de moleque e nos disse que justiça é algo difícil de se conseguir, mas que não deveríamos desistir.

Eu preferia balas de limão mas, de qualquer maneira, foi legal da parte dele.

"Pra onde nós vamos agora?"

"Visitar Laetitia".

O guarda que veio em direção ao nosso carro estava todo sorridente. As luzes da televisão eram tão fortes que machucavam meus olhos e, se eu tentasse olhar através do para-brisa, em algumas direções, não conseguia ver nada.

"Bom dia, senhora".

"Bom dia".

"Pra onde estão indo?"

"Salt Lake City".

"Motivo da visita?"

"Visitar minha filha".

"Estão levando tabaco, álcool ou armas de fogo?"

"Não fumo". 


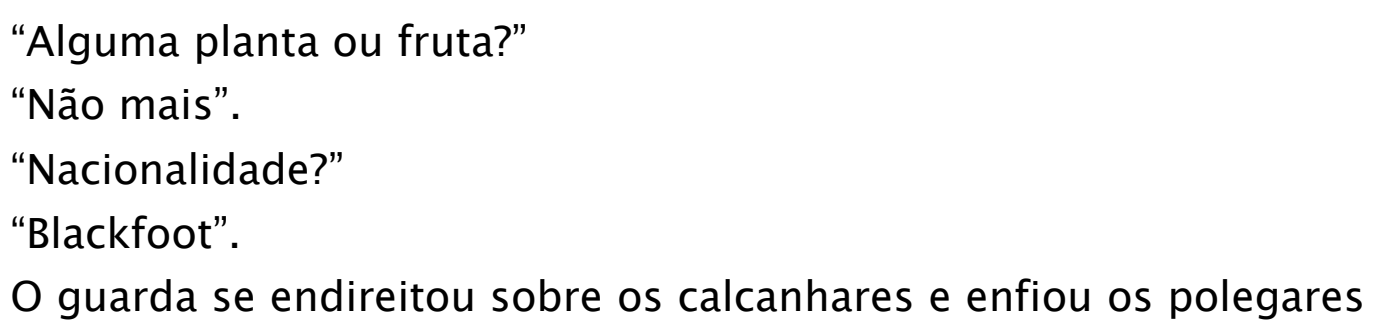
no cinturão. "Obrigado", disse ele, esfregando os dedos no revólver. "Tenham uma boa viagem".

Minha mãe seguiu em frente, e o pessoal da televisão teve que sair do caminho. Correram ao lado do carro à medida que nos afastávamos da fronteira e, quando não puderam mais correr, ficaram no meio da estrada e abanaram sem parar.

Chegamos a Salt Lake City no dia seguinte. Laetitia estava feliz em nos ver e, na primeira noite, nos levou a um restaurante que fazia sopas muito boas. A lista de tortas ocupava uma página inteira do menu. Pedi uma de cereja. Minha mãe pediu uma de chocolate. Laetitia disse que nos viu na televisão na noite anterior e, durante a janta, ela nos fez repetir a história diversas vezes.

Laetitia nos levou a todos os lugares. Fomos a uma estação de esqui chique. Fomos ao templo. Fizemos compras em alguns shopping centers grandes, mas não tão grandes quanto o de Edmonton, e minha mãe comentou isso.

Depois de cerca de uma semana, fiquei entediado e não fiquei triste quando minha mãe disse que devíamos voltar para casa. Laetitia queria que ficássemos mais, mas minha mãe disse não, que ela tinha coisas para fazer em casa e que, na próxima vez, era Laetitia quem deveria vir nos visitar. Laetitia disse que ela estava pensando em voltar, e minha mãe disse para ela fazer como achasse melhor, e Laetitia disse que faria.

No caminho de volta para casa, paramos no free shop, e minha mãe deu a Mel um boné verde que dizia "Salt Lake" na frente. Mel era um cara engraçado. Ele pegou o boné, assoou o nariz e disse a minha mãe que ela era uma inspiração para todos nós. Nos deu mais pés de moleque, e foi até o estacionamento e abanou para nós até chegarmos à fronteira canadense.

Era quase de noite quando saímos de Coutts. Observei a fronteira pela janela traseira, até que tudo o que se podia ver era o topo dos 
mastros das bandeiras e a torre de água azul, então eles atravessaram uma colina e desapareceram.

Espaço Ameríndio, Porto Alegre, v. 7, n. 2, p. 240-252, jul./dez. 2013. 